\title{
Identification and Validation of QTLs for Yield and Yield Components under Long-Term Salt Stress Using IR64 CSSLs in the Genetic Background of Koshihikari and Their Backcross Progenies
}

\author{
Nguyen Sao Mai ${ }^{1}{ }^{1}$, Dao Duy Hanh ${ }^{1}$, Mai Nakashima ${ }^{2}$, Kotaro Kumamoto ${ }^{2}$, Nguyen Thi Thu Thuy ${ }^{1}$, \\ Tohru Kobata $^{3}$, Kuniyuki Saitoh ${ }^{1}$ and Yoshihiko Hirai ${ }^{1, *}$ (D) \\ 1 Graduate School of Environmental and Life Science, Okayama University, 1-1-1 Tsushima-naka, Kita-ku, \\ Okayama 700-8530, Japan; saomai.bio@gmail.com (N.S.M.); dao-duyhanh@people.kobe-u.ac.jp (D.D.H.); \\ ntt-thuy@biomassfuelvn.com (N.T.T.T.); ksaitoh@okayama-u.ac.jp (K.S.) \\ 2 Faculty of Agriculture, Okayama University, 1-1-1 Tsushima-naka, Kita-ku, Okayama 700-8530, Japan; \\ ary12525@gmail.com (M.N.); pem90det@s.okayama-u.ac.jp (K.K.) \\ 3 Faculty of Life and Environmental Science, Shimane University, 1060 Nishikawatsu-cho, Matsue, \\ Shimane 690-8504, Japan; kobata@life.shimane-u.ac.jp \\ * Correspondence: yhirai@okayama-u.ac.jp; Tel.: +81-86-251-8316
}

Citation: Mai, N.S.; Hanh, D.D.; Nakashima, M.; Kumamoto, K.; Thuy, N.T.T.; Kobata, T.; Saitoh, K.; Hirai, Y Identification and Validation of QTLs for Yield and Yield Components under Long-Term Salt Stress Using IR64 CSSLs in the Genetic Background of Koshihikari and Their Backcross Progenies. Agriculture 2021 11,777. https://doi.org/10.3390/ agriculture11080777

Academic Editor: Ming Chen

Received: 12 July 2021

Accepted: 13 August 2021

Published: 15 August 2021

Publisher's Note: MDPI stays neutral with regard to jurisdictional claims in published maps and institutional affiliations.

Copyright: (C) 2021 by the authors Licensee MDPI, Basel, Switzerland. This article is an open access article distributed under the terms and conditions of the Creative Commons Attribution (CC BY) license (https:// creativecommons.org/licenses/by/ $4.0 /)$

\begin{abstract}
Unraveling the complex genetic bases and mechanisms underlying salt tolerance is of great importance for developing salt-tolerant varieties. In this study, we evaluated 42 chromosome segment substitution lines (CSSLs) carrying chromosome segments from IR64 on the genetic background of Koshihikari under salt stress. Two CSSLs, SL2007 and SL2038, produced higher plant dry weight and grain yield than did Koshihikari under the stress condition. These CSSLs also showed lower $\mathrm{Na}^{+}$and $\mathrm{Cl}^{-}$accumulation in the leaf and whole plant at the full heading stage, which might be related to the higher grain yield and yield components. To understand the genetic control of its grain yield and yield components, a SL2007/Koshihikari $\mathrm{F}_{2}$ population was generated for quantitative trait locus (QTL) analysis. Six QTLs for grain yield and yield-related traits were detected on chromosome 2. Using near-isogenic lines (NILs) from a SL2007/Koshihikari $\mathrm{F}_{5}$ population, qSTGY2.2 was delimited to a $2.5 \mathrm{Mb}$ region and novel $q S T P N 2$ was delimited to a $0.6 \mathrm{Mb}$ region. We also detected a novel QTL, qSTGF2, for grain filling, which was considered an important contributor to grain yield under salt stress in this CSSL. Our results provide insights into mechanisms conferring grain yield under salinity stress and new genetic resources for cloning and breeding.
\end{abstract}

Keywords: QTL; salt tolerance; grain yield; yield components; reproductive stage

\section{Introduction}

Rice is a staple crop feeding the largest number of people on Earth, and it provides approximately one-quarter of global energy consumption per capita [1]. The human population is projected to increase to 9.6 billion in 2050; therefore, rice production, together with other agricultural production, must double to meet the population's demand [2,3]. However, salt stress, one of the major hindrances to rice production, already affects nearly $10 \%$ of the total land surface of the Earth [4], eliminating 3 ha of arable land in each passing minute [5]. The situation is becoming more urgent as millions of hectares of suitable land areas used especially for rice production in South and Southeast Asia, responsible for 90\% of rice production worldwide, have been left uncultivated [6-8]. This calls for breeding salt-tolerant varieties with high yields to ensure food security and reutilize the land made unproductive by salt accumulation.

The rice response to salt stress differs greatly according to its growth stage: it is tolerant at the germination, tillering, and maturity stages but sensitive at the seedling and reproductive 
stages [9-11]. Salt tolerance at the seedling stage does not always correlate with salt tolerance at the reproductive stage [12] and it was reported that different genes might regulate salt tolerance at these stages [13]. Salt stress imposed on panicle initiation significantly inhibits panicle development by delaying panicle emergence and reducing the number of fertile tillers, and it adversely affects fertilization, reducing pollen viability and stigmatic receptivity [14]. Similarly, salinity exposure throughout the reproductive stage also delays flowering time, decreases the number of fertile tillers and spikelets per panicle, alters flower structures, and strongly decreases yield [15]. Recently, it was reported that salt stress produces deleterious effects on grain yield and yield parameters such as grain number, length, width, thickness, and grain filling percentage [16]. As grain yield and yield contributors are severely depressed, tolerance at the reproductive stage deserves special attention.

Overcoming ionic stress caused by $\mathrm{Na}^{+}$and $\mathrm{Cl}^{-}$is a fundamental challenge of rice plants under salt stress because it results in severe ion imbalance and causes physiological disorders [17-20]. Possible mechanisms by which rice plants cope with ionic stress involve: minimizing toxic ion entry through their roots, restricting excessive ion transportation to shoots [8], allocating higher ion concentrations in their older leaves [12], maintaining low ion concentrations within the cytoplasm, and sequestering $\mathrm{Na}^{+}$and $\mathrm{Cl}^{-}$in vacuoles [11]. Flowers and Yeo [21] reported that there is a negative correlation between $\mathrm{Na}^{+}$and $\mathrm{Cl}^{-}$ concentrations in shoots and survival under salt stress conditions of varieties. Many studies have witnessed a strong association between excluding sodium from shoots and salt tolerance in rice varieties [22-25]. A closer correlation was found between grain yield and $\mathrm{Na}^{+}$and $\mathrm{Cl}^{-}$contents at full heading than at the panicle initiation and mature stages [26]. However, our understanding of the relationship between the ion contents at growth stages and grain yield under salt stress conditions is still limited.

Since salt tolerance is governed by quantitative trait loci (QTLs), to gain knowledge on salt tolerance mechanisms and for breeding purposes, intense efforts have been made regarding QTL mapping. Numerous QTLs were detected for salt tolerance at the seedling stage in rice [27-36]. Among them, a famous QTL, Saltol, with large effects was identified, and it has been used for developing salt-tolerant cultivars across many countries [37-39]. Another major QTL, qSKC-1 [27], was fine-mapped and cloned [40,41]. By contrast, fewer studies have focused on salt tolerance at the reproductive stage [42-47]. Moreover, none of the detected QTLs for salt tolerance at the reproductive stage have been fine-mapped or cloned.

Drilling for genetic factors controlling these salt-tolerant traits in different varieties [48] is useful for breeding programs via the pyramiding approach. IR64, 'a high-quality and high-yielding mega variety', was reported to be moderately tolerant to salinity stress at the seedling stage with a visual salt injury score (following IRRI's assessment) of 5.8, while those of salt-tolerant landraces Pokkali and Nona Bokra are 4.2 and 4.1, respectively $[49,50]$. As salt tolerance traits are expressed unequally in rice genotypes, moderately tolerant varieties might possess characteristics independent from those of tolerant varieties. Furthermore, very little is known about salinity tolerance at the reproductive stage of these varieties. This study aimed: (1) to screen the salt tolerance of 42 IR64 chromosome segment substitution lines (CSSLs) under salt stress conditions; (2) to examine physiological characteristics associated with the salt tolerance of selected CSSLs showing superior tolerance to Koshihikari; (3) to map QTLs for grain yield and yield components under salt stress conditions by using an SL2007/Koshihikari $F_{2}$ population; and (4) to validate and fine-map the detected QTLs on the long arm of chromosome 2 by comparing NILs. Furthermore, we compared these results with our group's previous results on the screened salt tolerance of 44 CSSLs derived from Nona Bokra and Koshihikari in a relatively parallel manner [26] to see the differences in salt tolerance between IR64 and the salt-tolerant benchmark Nona Bokra.

\section{Materials and Methods}

\subsection{Plant Materials}

A set of 42 IR64-CSSLs on the Koshihikari genetic background (SL2001-SL2042) and their recipient parent, Koshihikari, were received from the Rice Genome Resource Center 
2014:

Screening of CSSLs in Japan. Seeds of IR64 were received from IRRI. The graphical genotypes of IR64-CSSLs were published previously [51]. Our experimental plan was illustrated in Figure 1. The CSSLs and their parents were firstly evaluated under non-stress and salt stress conditions in 2014. Since four CSSLs (SL2007, SL2008, SL2027, and SL2038) produced higher panicle weight under the salt stress condition, they were used for detailed physiological analysis in 2015. The CSSL SL2007 carries IR64 segments on chromosomes 2 and 10 on the genetic background of Koshihikari. As it has shown consistently higher performance than Koshihikari under salt stress conditions in the 2014 and 2015 experiments, we considered this CSSL to possess potential genetic factors for salt tolerance. Consequently, to carry out QTL analysis, the CSSL was crossed with the recipient parent, Koshihikari, to produce an $\mathrm{F}_{2}$ population for QTL analysis in 2016. Finally, to validate and narrow down the detected QTL intervals on the long arm of chromosome 2, four NILs containing different QTLs were selected from the SL2007/Koshihikari $F_{5}$ population using 12 SSR and Indel markers, and they were evaluated in 2018.

\section{Kosh \\ Koshihikari IR64}

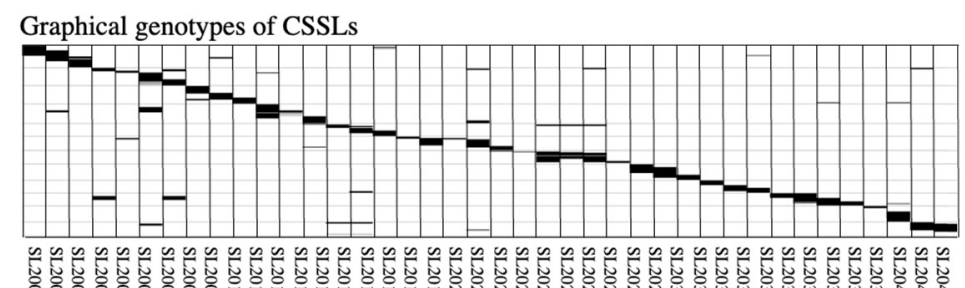

2015:

Analysis of salt-tolerant CSSLs

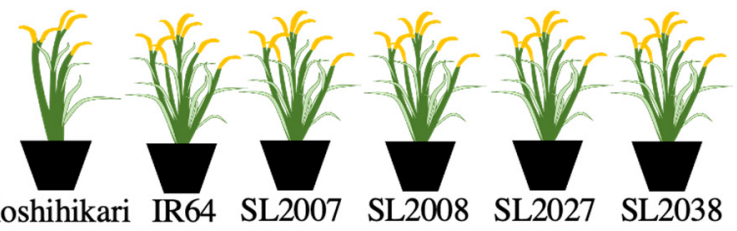

Koshihikari IR64 SL2007 SL2008 SL2027 SL2038

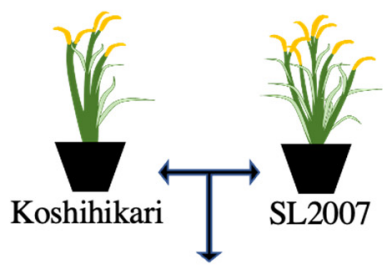

2016:

QTL analysis on $F_{2}$ population

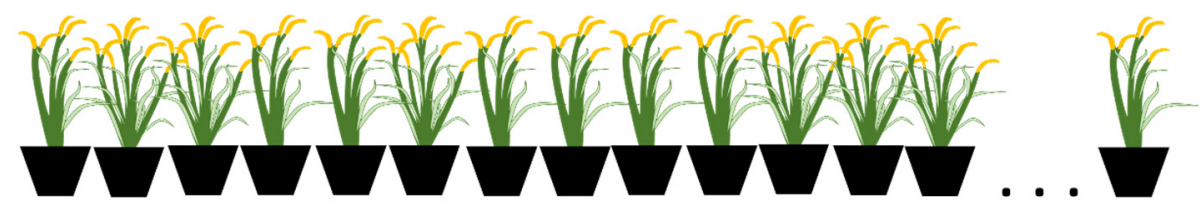

2018:

Validation of detected QTLs

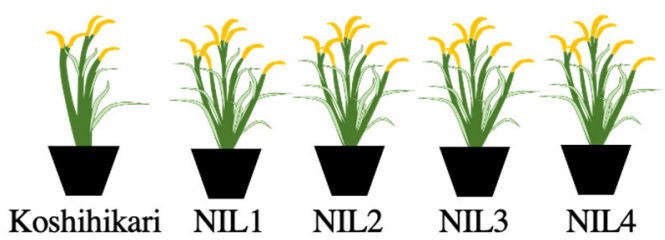

Figure 1. Schematic representation of the experimental design.

\subsection{Growing Conditions and Salt Treatment}

The experiments were conducted at the experimental field of the Faculty of Agriculture, Okayama University, Japan $\left(34,041^{\prime} \mathrm{N}, 133,055^{\prime} \mathrm{N}\right)$ in 2014-2018. Seeds were surface-sterilized with $0.1 \%$ Benlate fungicide and then soaked in tap water for two days before seeding. Uniform germinated seeds were sowed in nursery boxes (Minoru pot 448, Minoru Industrial Co. Ltd., Okayama, Japan) with 448 holes (16 mm diameter, $25 \mathrm{~mm}$ depth) filled with nursery soil (Kumiai Ube Ryu-Joh Baido, Ube Industries Ltd., Tokyo, Japan). The seeding days of each 
experiment were 23 May 2014, 15 May 2015, 23 May 2016, and 8 June 2018. Twenty-day-old seedlings were transferred into 2L pots (No. 5.5, Kaneya co. LTD, Aichi, Japan) containing paddy soil, well mixed with $8 \mathrm{~g}$ LPS 140E-80 slow-release fertilizer (NPK 14-14-14). Those pots were arranged with a spacing of $25 \mathrm{~cm}$ between them and kept flooded with tap water in a pool $(20 \mathrm{~m} \times 1.1 \mathrm{~m} \times 0.18 \mathrm{~m})$ under a two-sided opened vinyl house. For salt stress treatment, $\mathrm{NaCl}$ was applied at 7 days and 10 days after transplanting to induce saline conditions with an electrical conductivity (EC) of approximately $7 \mathrm{dSm}^{-1}$. For control, $\mathrm{NaCl}$ was not added. Water was supplied through an irrigation tube (Evaflow Type-A, Mitsui Chemicals, Tokyo, Japan), and the electrical conductivity in the pond water was measured using an EC meter (2265FS, Spectrum Technologies, Inc., Aurora, IL, US). The EC of the ponded water was kept stable until the maturity stage.

\subsection{Phenotypic Evaluation}

To screen for salt tolerance, plants were harvested 45 days from the recorded heading date under control and stress conditions. The leaf and stem were oven-dried at $80{ }^{\circ} \mathrm{C}$ for three days, following which the dry weight was measured. The panicle weight was measured after drying at $35^{\circ} \mathrm{C}$ for $72 \mathrm{~h}$, and grains were then separated into unfilled and filled grains using a 1.06 specific gravity $\mathrm{NaCl}$ solution. In 2014, we firstly screened IR64 CSSLs by using two morphological traits: plant dry weight (DW) and panicle weight (PW). In 2015 and 2018, we measured a total of seven morphological traits: DW, PW, panicle number (PN), grain yield (GY), spikelet number per panicle (SN), 1000-grain weight (TGW), and grain filling (GF). Four phenotypic traits-DW, PW, PN, and GY-were recorded in $70 \mathrm{~F}_{2}$ plants for QTL analysis in 2016.

\subsection{Ion Measurement of Selected Chromosome Segment Substitution Lines (CSSLs)}

Ion contents in selected lines and their parents in 2015 were measured at the full heading stage ( 3 days after heading). Four replicates of each line were harvested, and then the leaf blade (LB) and leaf sheath (LS) were separated. Samples were dried at $80{ }^{\circ} \mathrm{C}$ for $72 \mathrm{~h}$ before ion measurement. The $\mathrm{Na}^{+}$content was measured using a flame photometer (BWB-XP, BWB Technologies, Berkshire, UK), and the $\mathrm{Cl}^{-}$content was measured using a $\mathrm{pH} /$ ion meter (D-53, Horiba Ltd., Tokyo, Japan) [26]. Briefly, $0.5 \mathrm{~g}$ samples were chopped and extracted with $25 \mathrm{~mL}$ of $1 \%$ nitric acid at $80^{\circ} \mathrm{C}$ for $24 \mathrm{~h}$. The ion content of the whole plant (WP) was calculated based on all parts' ion contents and plant dry weight.

\subsection{DNA Extraction and Polymerase Chain Reaction (PCR) Analysis}

DNA extraction and amplification through polymerase chain reaction (PCR) followed a method described by [52] with slight modification. DNA was extracted from leaf samples of the $\mathrm{F}_{2}$ population and two parents using SDS/ $\mathrm{NaCl}$ extraction buffer and then genotyped using 19 polymorphic SSR and indel markers. PCR amplification was carried out in $10 \mu \mathrm{L}$ reactions containing $1.5 \mu \mathrm{L}$ DNA template, $3 \mu \mathrm{L}$ Milli-Q water, $5 \mu \mathrm{L}$ Taq DNA polymerase, and $0.25 \mu \mathrm{L}$ each of $10 \mu \mathrm{M}$ forward and reverse primers. PCR was performed using thermal cycler (TP600, Takara Bio Inc., Shiga, Japan) by initial denaturation at $95{ }^{\circ} \mathrm{C}$ for $2 \mathrm{~min}$; then 35 cycles of denaturation at $95^{\circ} \mathrm{C}$ for $20 \mathrm{~s}$, annealing at $50{ }^{\circ} \mathrm{C}$ for $20 \mathrm{~s}$, and extension at $72{ }^{\circ} \mathrm{C}$ for $30 \mathrm{~s}$; and a final extension at $72{ }^{\circ} \mathrm{C}$ for $2 \mathrm{~min}$ and storage at $15{ }^{\circ} \mathrm{C}$ The PCR products were stained with Midori green direct stain (Nippon Genetics Co. Ltd., Tokyo, Japan), and DNA fragments were separated on 3\% agarose gel for manual allele scoring.

\subsection{Quantitative Trait Locus (QTL) Mapping}

Based on the genotypic data of the $\mathrm{F}_{2}$ plants, a linkage map was constructed using MAPMAKER/EXP 3.0b software. The chromosomal positions and effects of putative QTLs were determined by composite interval mapping in QTL Cartographer 2.5 software. The threshold of QTL detection was based on 1000 permutation tests at a 5\% level of significance. The additive and dominant effects and phenotypic variance explained by each QTL $\left(\mathrm{R}^{2}\right)$ were estimated from the peak LOD score. 


\subsection{Statistical Analysis}

Dunnett's multiple comparison test at probability levels of $5 \%, 1 \%$, and $0.1 \%$ was used to detect any significant differences between CSSLs or NILs and Koshihikari. Correlations between the studied traits were determined using Pearson's correlation in JMP software version 9.0.

\section{Results}

\subsection{Salt Tolerance Evaluation of CSSLS}

In 2014, IR64-CSSLs were grown under non-stress and salt stress conditions to identify CSSLs showing higher tolerance to salt stress as compared with the sensitive recipient, Koshihikari. Under non-stressed conditions, only SL2038 showed significantly higher DW than the recipient (Figure 2A). The four lines SL2002, SL2006, SL2010, and SL2011 showed PW values lower than that of Koshihikari (Figure 3A).

Exposure to $\mathrm{NaCl}$ stress with an EC of around $7 \mathrm{dSm}^{-1}$ for an extended period from the vegetative stage to the maturity stage caused a reduction in both DW and PW in all lines; however, the reduction varied considerably among the parents and CSSLs (Figures 2B and 3B). DW significantly decreased by $72 \%$ in Koshihikari but only $16 \%$ in IR64. The reduction in DW of the CSSLs varied in the range of 33-84\%. Among the CSSLs, SL2012 and 2038 produced significantly higher DW as compared with Koshihikari. In terms of PW, salt stress also caused a more considerable reduction in Koshihikari than in IR64, with decreases of $84 \%$ and $70 \%$, respectively. The decline in the PW of CSSLs varied in the range of 43-91\%. Together with IR64, three lines (SL2007, SL2008, and SL2038) showed significantly higher PW than Koshihikari.

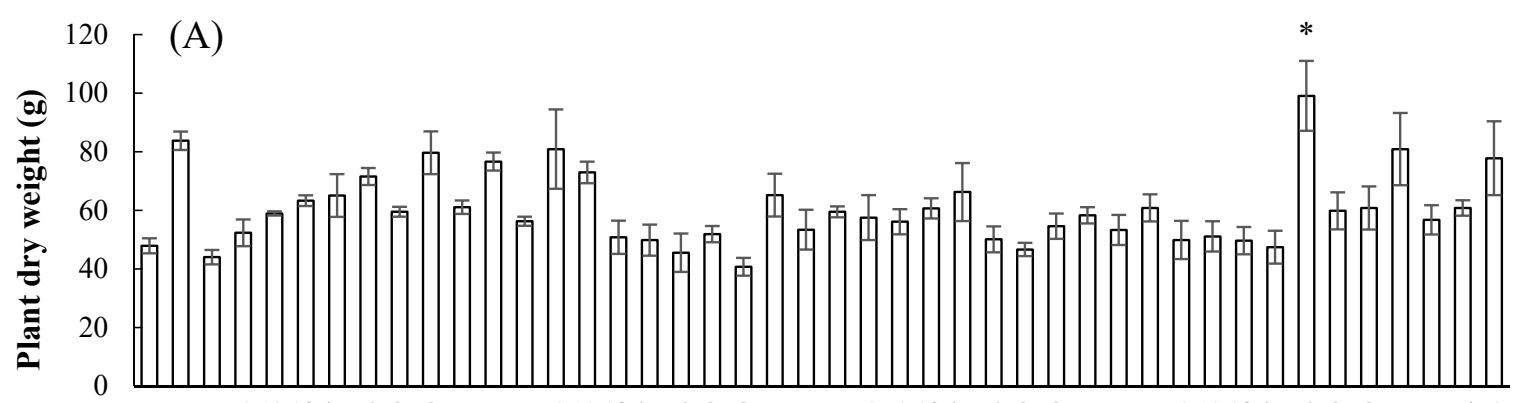

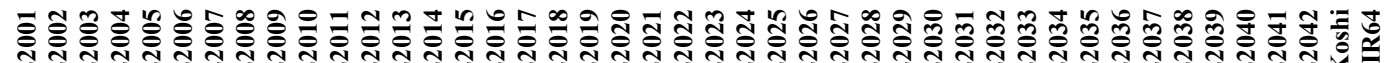

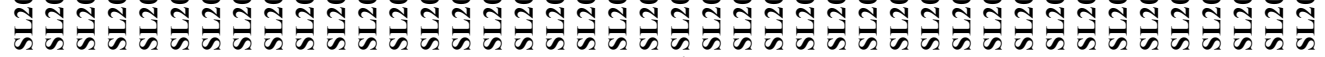
Lines

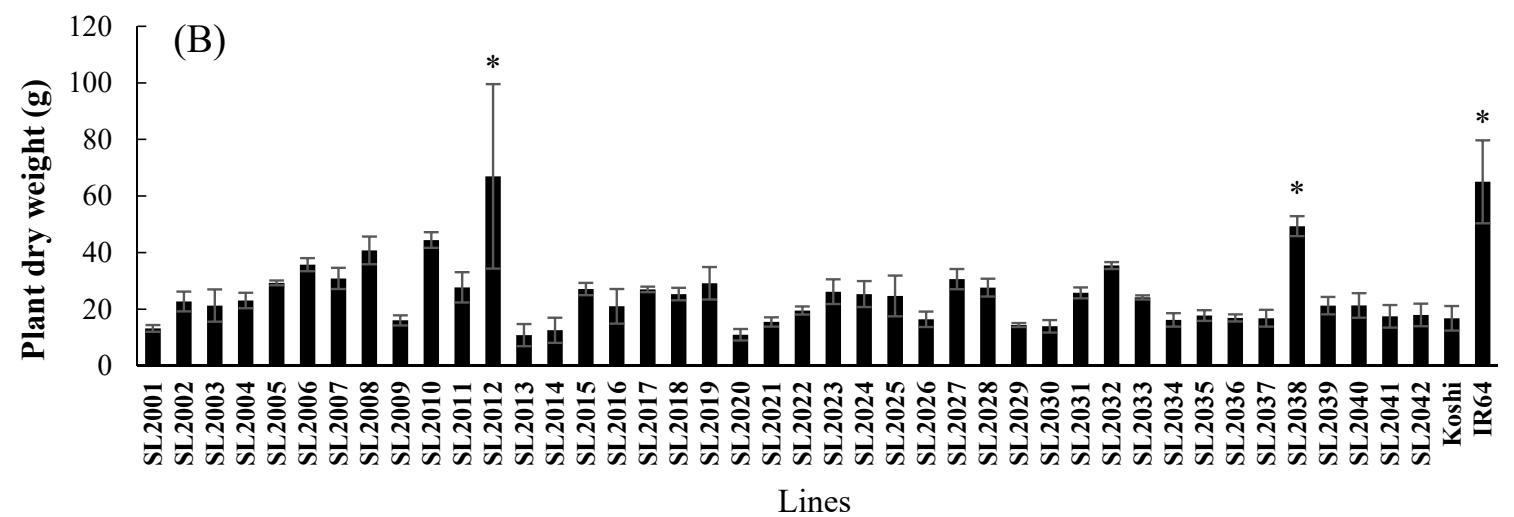

Figure 2. Plant dry weight values of 42 chromosome segment substitution lines (CSSLs) and parents under (A) non-stress and (B) salt stress conditions in 2014. Values are mean \pm standard error $(n=3) .{ }^{*}$ indicates a significant difference between Koshihikari and CSSL at the 5\% level by Dunnett's test. 

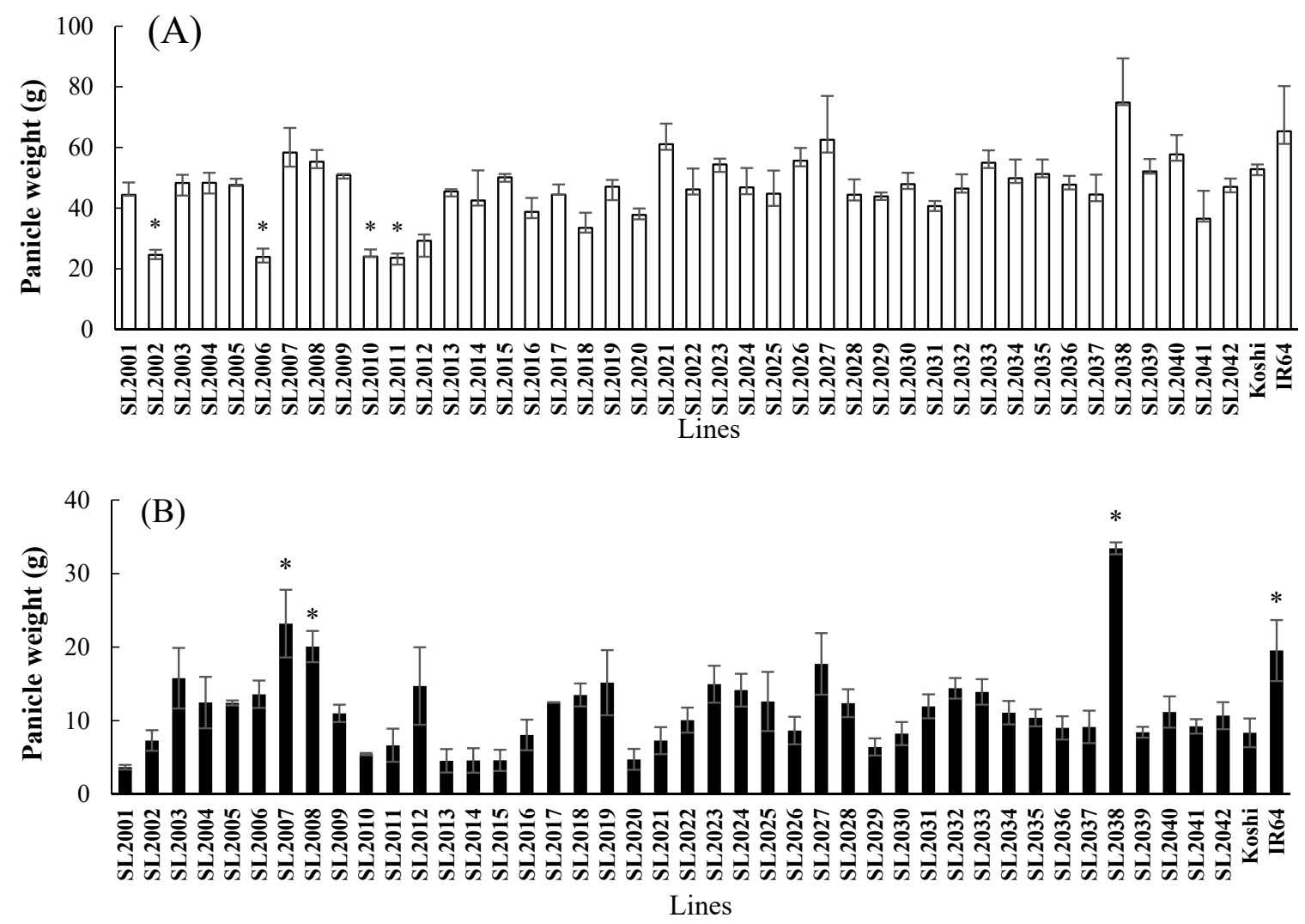

Figure 3. Panicle weight values of 42 CSSLs and parents under (A) non-stress and (B) salt stress conditions in 2014. Values are mean \pm standard error $(n=3) .{ }^{*}$ indicates a significant difference between Koshihikari and CSSL at the $5 \%$ level by Dunnett's test.

\subsection{Physio-Morphological Analysis of Salt-Tolerant CSSLS \\ 3.2.1. Yield and Yield Components}

Four CSSLs (SL2007, SL2008, SL2027, and SL2038) exhibiting higher salt tolerance than the recipient parent, Koshihikari, were selected to study their physiological mechanisms in tolerating salt stress in detail. A similar trend was observed as salt stress markedly decreased DW, GY, and yield components in all genotypes. Under salt stress conditions, IR64 showed significant differences from Koshihikari in DW, PN, PW, GY, GF, and TGW (Figure 4). Among the selected CSSLs, SL2007, carrying IR64 chromosomal segments on chromosomes 2 and 10, produced significantly higher DW, PW, PN, and GY as compared with Koshihikari. Another CSSL, SL2038, which possesses IR64 segments on chromosomes 3 and 11, showed higher DW, PW, PN, GF, and TGW than Koshihikari.

\subsubsection{Ion Contents}

We measured the $\mathrm{Na}^{+}$and $\mathrm{Cl}^{-}$contents in the leaf sheath, leaf blade, and whole plant at full heading to examine how ion accumulations relate to yield and yield components. Relevant to both ion contents, IR64 showed lower accumulation in the leaf blade, leaf sheath, and whole plant than did Koshihikari (Table 1). Akin to IR64, SL2007 showed significantly lower $\mathrm{Na}^{+}$and $\mathrm{Cl}^{-}$contents in all the measured organs than did Koshihikari. The CSSL SL2038 showed significantly lower values in both ion contents in the leaf sheath and the whole plant in comparison with the recipient. SL2008 showed significantly lower $\mathrm{Na}^{+}$ content in all measured organs and $\mathrm{Cl}^{-}$content in the leaf blade than Koshihikari. SL2027 only showed a significant difference to Koshihikari in the $\mathrm{Cl}^{-}$content in the leaf blade. 

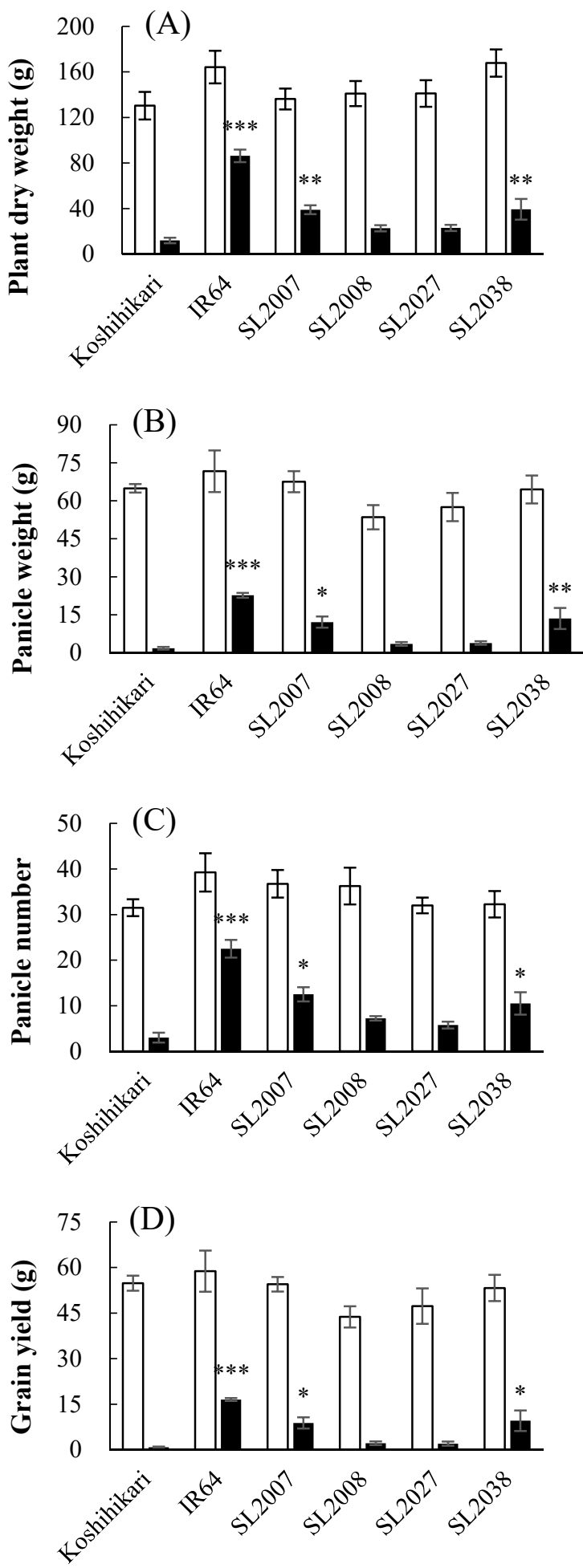

Figure 4. Cont. 

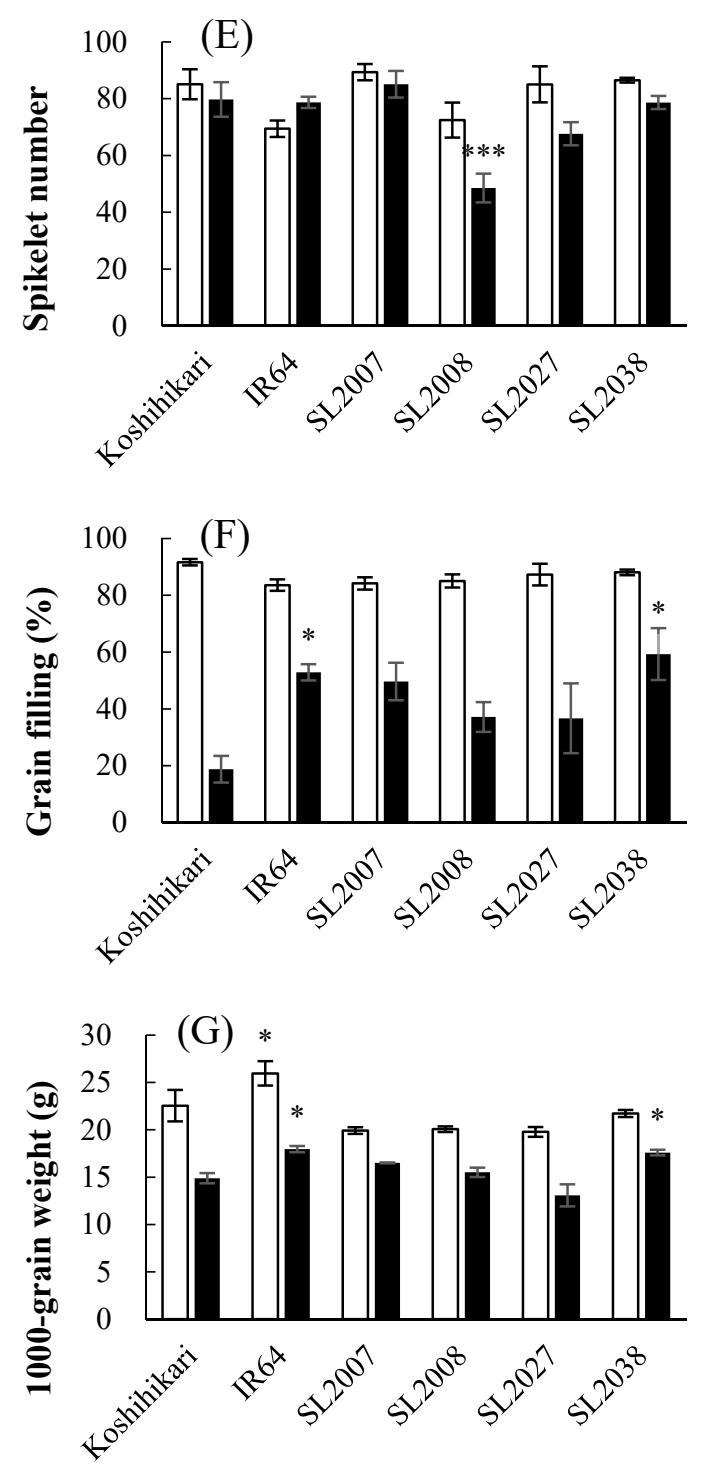

Figure 4. (A) Plant dry weight, (B) panicle weight, (C) panicle number, (D) grain yield, (E) spikelet number per panicle, (F) grain filling, and (G) 1000-grain weight of SL2007, SL2008, SL2027, SL2038, Koshihikari, and IR64 under non-stress and stress conditions in 2015. White bars and black bars denote plant performance under non-stress and stress conditions, respectively. Values are mean \pm standard error $(\mathrm{n}=4){ }^{*},{ }^{* *}$, and ${ }^{* * *}$ indicate significant differences from Koshihikari under the non-stress or salt stress condition at the $5 \%, 1 \%$, and $0.1 \%$ levels by Dunnett's test, respectively.

Table 1. $\mathrm{Na}^{+}$and $\mathrm{Cl}^{-}$contents in the leaf blade, leaf sheath, and whole plant at the full heading stage of Koshihikari, IR64, and selected CSSLs under salt stress conditions in 2015. Values are mean \pm standard error $(n=4) .{ }^{*}, *$, and ${ }^{* * *}$ indicate a significant differences from Koshihikari at the $5 \%, 1 \%$, and $0.1 \%$ levels by Dunnett's test, respectively.

\begin{tabular}{ccccccc}
\hline & \multicolumn{3}{c}{$\mathbf{N a}^{+}$Content (mmol/g) } & \multicolumn{3}{c}{ Cl $^{-}$Content (mmol/g) } \\
\cline { 2 - 7 } & LB & LS & WP & LB & LS & WP \\
\hline Koshihikari & $1.19 \pm 0.11$ & $1.41 \pm 0.17$ & $1.26 \pm 0.16$ & $1.70 \pm 0.12$ & $1.43 \pm 0.12$ & $1.25 \pm 0.16$ \\
IR64 & $0.70 \pm 0.14^{*}$ & $0.77 \pm 0.15^{* * *}$ & $0.70 \pm 0.10^{* * *}$ & $1.04 \pm 0.17^{* * *}$ & $1.01 \pm 0.09^{* *}$ & $0.90 \pm 0.06^{*}$ \\
SL2007 & $0.72 \pm 0.07^{*}$ & $0.92 \pm 0.09^{* *}$ & $0.77 \pm 0.06^{* *}$ & $1.20 \pm 0.10^{* *}$ & $1.04 \pm 0.05^{* *}$ & $0.81 \pm 0.044^{* *}$ \\
SL2008 & $0.76 \pm 0.05^{*}$ & $1.06 \pm 0.04^{*}$ & $0.89 \pm 0.07^{*}$ & $1.18 \pm 0.01^{* *}$ & $1.19 \pm 0.05$ & $1.17 \pm 0.08$ \\
SL2027 & $0.81 \pm 0.10$ & $1.39 \pm 0.10$ & $1.15 \pm 0.14$ & $1.26 \pm 0.12^{*}$ & $1.43 \pm 0.07$ & $1.44 \pm 0.10$ \\
SL2038 & $0.83 \pm 0.10$ & $0.97 \pm 0.14^{*}$ & $0.85 \pm 0.15^{*}$ & $1.34 \pm 0.11^{*}$ & $1.14 \pm 0.10^{*}$ & $0.97 \pm 0.11$ \\
\hline
\end{tabular}

(LB, leaf blade; LS, leaf sheath; WP, whole plant). 


\subsubsection{Correlation between Traits}

The DW, GY, and yield parameters were used in this study to estimate the combined effects of salt stress after a long period. It is interesting to examine whether yield and yield-related traits correlate with ion contents. Strong correlations between ion contents at the full heading stage and GY and ancillary traits were observed (Table 2). The $\mathrm{Na}^{+}$ content in the leaf blade, leaf sheath, and whole plant exhibited significant and negative correlations with DW, PW, PN, GY, TGW, and GF. In agreement with the $\mathrm{Na}^{+}$content, the $\mathrm{Cl}^{-}$content in all organs also significantly and negatively correlated with these traits. Interestingly, both $\mathrm{Na}^{+}$and $\mathrm{Cl}^{-}$contents showed virtually no correlation with $\mathrm{SN}$.

Table 2. Pearson correlation coefficients between ion contents and grain yield and yield-related traits of Koshihikari and selected CSSLs under salinity in 2015. Values are mean \pm standard error $(n=4)$. ${ }^{*}$ and ${ }^{* *}$ indicate significant differences at the $5 \%$ and $1 \%$ levels, respectively.

\begin{tabular}{ccccccccc}
\hline & & DW & PW & PN & GY & SN & TGW & GF \\
\hline \multirow{2}{*}{$\mathrm{Na}^{+}$} & LB & $-0.510^{*}$ & -0.352 & $-0.475^{*}$ & -0.358 & 0.215 & -0.257 & $-0.634^{* *}$ \\
content & LS & $-0.615^{* *}$ & $-0.540^{*}$ & $-0.640^{* *}$ & $-0.535^{*}$ & 0.009 & $-0.596^{* *}$ & $-0.589^{* *}$ \\
& WP & $-0.643^{* *}$ & $-0.536^{*}$ & $-0.671^{* *}$ & $-0.535^{*}$ & 0.049 & $-0.557^{*}$ & $-0.602^{* *}$ \\
\hline \multirow{3}{*}{$\mathrm{Cl}^{-}$content } & LB & -0.439 & -0.275 & -0.397 & -0.263 & 0.298 & -0.196 & $-0.543^{*}$ \\
& LS & $-0.621^{* *}$ & $-0.548^{*}$ & $-0.659^{* *}$ & $-0.549^{*}$ & -0.029 & $-0.558^{*}$ & $-0.585^{* *}$ \\
& WP & $-0.602^{* *}$ & $-0.579^{* *}$ & $-0.634^{* *}$ & $-0.582^{* *}$ & -0.301 & $-0.669^{* *}$ & $-0.536^{*}$ \\
\hline
\end{tabular}

(DW, plant dry weight; PW, panicle weight; PN, panicle number; GY, grain yield; SN, spikelet number; TGW, 1000-grain weight; GF, grain filling).

\subsection{Detection of QTLs for Salt Tolerance}

In 2016, 70 SL2007/Koshihikari $F_{2}$ plants were evaluated under salt stress conditions and genotyped using 19 SSR markers, among which 17 markers cover target regions on chromosome 2 and 2 markers flank a target region on chromosome 10. All the studied phenotypic traits, including DW, $\mathrm{PN}, \mathrm{PW}$, and GY of the $\mathrm{F}_{2}$ population, showed continuous distributions (data not shown). A linkage map was constructed using $70 \mathrm{~F}_{2}$ plants and 19 SSR markers. Composite interval mapping detected six QTLs on chromosome 2 for all measured phenotypic traits (Table 3). The QTLs detected in this study explain 9.91-31.84\% of the phenotypic variance with LOD values ranging from 2.71 to 4.70 . A QTL was detected for DW, qSTDW2, in the interval between RM13648 and RM13755 on the long arm of chromosome 2, the additive effects of which are derived from IR64 alleles. Two QTLs were detected for GY, qSTGY2.1 and qSTGY2.2, at LOD values of 3.72 and 3.85. The qSTGY2.1, explaining $23.64 \%$ of the phenotypic variation, was mapped on the short arm of chromosome 2 between markers RM12674 and RM12857, and Koshihikari alleles increased GY in this position. Another QTL, qSTGY2.2, explaining 31.84\% of the phenotypic variation, was detected in the interval between RM13796 and RM5607 on the long arm of chromosome 2. Alleles from IR64 contributed to the additive effect on this QTL region. One QTL for PN, qSTPN2, explaining the highest phenotypic variance of 33.09\%, was mapped to the region between RM13648 and RM13893. IR64 alleles also provided an increased effect on PN in this region. Two QTLs were mapped for PW, qSTPW2.1 and qSTPW2.2, with $10.39 \%$ and $24.51 \%$ of the phenotypic variation. Whereas $q S T P W 2.1$ was co-localized with $q S T G Y 2.1$, qSTPW2.2 was mapped to the same QTL region as qSTGY2.2. Alleles from both parents provided increased effects on PW. The region of two co-localized QTLs, qSTGY2.1 and qSTPW2.1, is similar to that of previously detected QTLs for GY $[42,44,46,53]$.

\subsection{Validation and Fine Mapping of Detected QTLs}

Since QTLs for DW, PN, PW, and GY detected on the long arm of chromosome 2 explained high phenotypic variations, narrowing down further and validating their regions was noteworthy. Using 12 polymorphic SSR and Indel markers, we screened recombinants from the SL2007/Koshihikari $F_{5}$ population. As IR64 alleles provided positive effects on these QTLs, we selected four NILs carrying IR64 alleles in these QTL regions (Figure 5). 
NILs were evaluated for GY and ancillary traits under long-term salt stress conditions along with Koshihikari. Since only NIL1 showed significantly higher DW than Koshihikari, the $q S T D W 2$ was narrowed down to a $2.9 \mathrm{Mb}$ region between RM13593 and Indel 26.93. NIL1 and NIL2 produced around 1.6 times higher PN than Koshihikari and were confirmed to harbor the QTL for PN. This indicated that $q S T P N 2$ was delimited to a physical region of $0.6 \mathrm{Mb}$, flanked by RM13717 and Indel 27.25. NIL3 produced 2.2 and 3 times higher GY and PW than Koshihikari, respectively, which indicated that NIL3 contains QTLs for these traits. Thus, qSTGY2.2 and qSTPW2.2 were confirmed to a $2.5 \mathrm{Mb}$ region, flanked by RM13781 and RM13928. Furthermore, NIL3 and NIL4 yielded significantly higher GF than Koshihikari, which suggested the presence of a QTL for GF. This QTL, designated qSTGF2, was confined to a $2.3 \mathrm{Mb}$ region between RM13928 and Indel 31.98. The region of $q S T G Y 2.2$ coincides with a QTL region for GY, which was detected recently under salt stress conditions [54]. However, when it comes to qSTPN2 and qSTGF2, QTLs detected previously are in regions distinct from those of our QTLs [55]. Thus, qSTPN2 and qSTGF2 are novel QTLs for PN and GF under salt stress conditions.

Table 3. Quantitative trait loci (QTL) for grain yield and yield-related traits identified in the $\mathrm{F}_{2}$ population by composite interval mapping on chromosome 2.

\begin{tabular}{|c|c|c|c|c|c|c|}
\hline Trait & QTL & Marker Interval (Mb) & LOD & Additive & $\mathbf{R}^{2}$ & Parental Source ${ }^{a}$ \\
\hline Plant dry weight & qSTDW2 & $\begin{array}{c}\text { RM13648-RM13755 } \\
(25.47-27.45)\end{array}$ & 2.89 & -6.44 & 9.91 & I \\
\hline Panicle number & qSTPN2 & $\begin{array}{c}\text { RM13648-RM13893 } \\
(25.47-29.71)\end{array}$ & 4.70 & -3.67 & 33.09 & I \\
\hline \multirow[t]{2}{*}{ Panicle weight } & qSTPW2.1 & $\begin{array}{c}\text { RM12674-RM12857 } \\
(5.69-8.63)\end{array}$ & 2.71 & 1.07 & 10.39 & K \\
\hline & qSTPW2.2 & $\begin{array}{l}\text { RM13755-RM13893 } \\
\quad(27.45-29.71)\end{array}$ & 2.83 & -1.06 & 24.51 & I \\
\hline \multirow{2}{*}{ Grain yield } & qSTGY2.1 & $\begin{array}{c}\text { RM12674-RM12857 } \\
(5.69-8.63)\end{array}$ & 3.85 & 0.50 & 23.64 & K \\
\hline & qSTGY2.2 & $\begin{array}{l}\text { RM13796-RM5607 } \\
(28.27-33.27)\end{array}$ & 3.72 & -0.47 & 31.84 & I \\
\hline
\end{tabular}

a Parental sources of additive alleles: K (Koshihikari) and I (IR64).

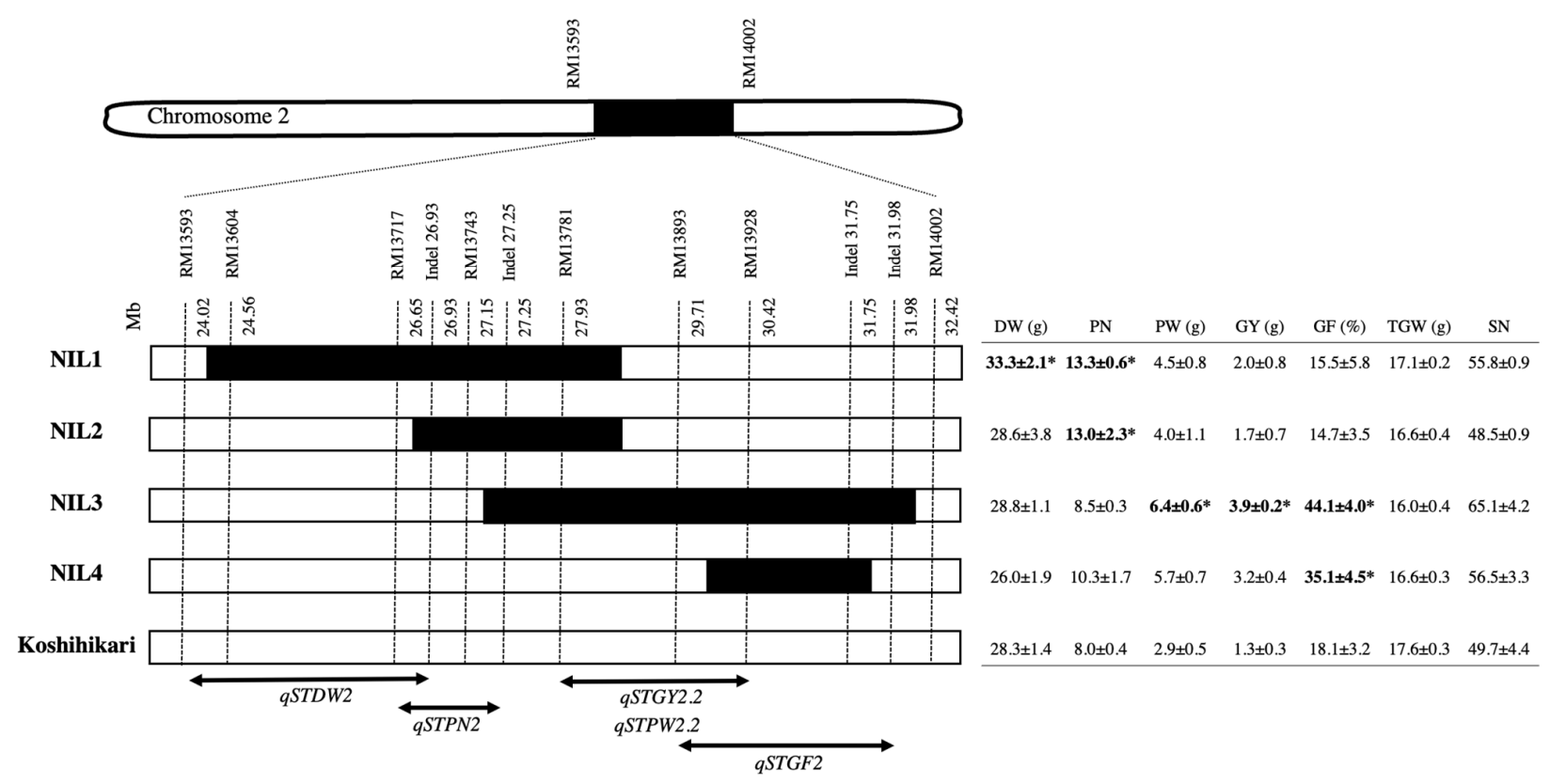

Figure 5. Graphical genotypes of near-isogenic lines (NILs) and their grain yield and ancillary traits under salt stress conditions in 2018. Black and white bars indicate chromosome segments for homozygous IR64 and Koshihikari, respectively. Values are mean \pm standard error $(n=4) .{ }^{*}$ indicates a significant difference between Koshihikari and NILs at a $5 \%$ level by Dunnett's test. 


\section{Discussion}

In the present study, we evaluated the tolerance of 42 IR64-CSSLs in the genetic background of Koshihikari grown under salt stress conditions in 2014, covering vegetative and reproductive stages. During the salt treatment period, plants continued growing vegetatively and produced yield, so we observed adverse effects of salt stress on the DW and PW of all examined genotypes. Under saline conditions, there were two IR64-CSSLs with higher DW and three IR64-CSSLs with higher PW than Koshihikari (Figures 2B and 3B). Thuy et al. [26] evaluated the salt tolerance of 44 CSSLs carrying different Nona Bokra segments in the genetic background of Koshihikari under the same experimental conditions in 2014. Since 10 Nona Bokra-CSSLs were recorded with significantly higher DW than Koshihikari, introgressed Nona Bokra segments of these CSSLs distributing in almost every chromosome were considered putative contributors to this landrace's salt tolerance. Thus, compared with the salt-tolerant benchmark Nona Bokra, relatively tolerant IR64 possesses fewer chromosome segments that maintain high DW under salt stress. In other words, this suggests that the quantity of chromosomal regions involved in salt tolerance is closely related to the different extents of salt tolerance among cultivars. Notwithstanding this, comparing the positions of these salt-tolerant Nona Bokra and IR64 chromosome segments indicated some incompatible segments $[51,56]$. Substantial progress made in studies on rice revealed several key salt tolerance mechanisms that are not equally expressed in varieties [57]. Thus, we assumed that such particular segments might build up specific salt tolerance mechanisms in IR64. SL2038 consistently produced higher DW than Koshihikari under salt stress conditions in 2014 and 2015 (Figures 2B and 4A). Therefore, IR64 segments of chromosomes 3, 10, and 11 in SL2038 might be responsible for maintaining DW under salinity. Regarding PW, two CSSLs, SL2007 and SL2038, consistently showed higher performance than Koshihikari (Figures 3B and 4B). Consequently, IR64 chromosome segments of chromosomes 2, 3, 10, and 11 harbored in these CSSLs might be responsible for stably maintaining PW under salt stress conditions. Investigating physiological traits and yield components in SL2007 and SL2038 will give more insight into the mechanisms relating to salt tolerance at the reproductive stage in IR64.

Maintaining a low ion concentration in the shoot was reported to be an effective strategy of tolerant glycophytes [58]. Here, we observed a close relation between $\mathrm{Na}^{+}$and $\mathrm{Cl}^{-}$accumulations at the full heading stage and grain yield and ancillary traits (Table 2). Two salt-tolerant CSSLs, SL2007 and SL2038, produced higher DW, PW, PN, GY, GF, and TGW than Koshihikari and also accumulated significantly lower $\mathrm{Na}^{+}$and $\mathrm{Cl}^{-}$contents in the leaf blade, leaf sheath, and whole plant at the full heading stage than Koshihikari. A negative correlation was observed between $\mathrm{Na}^{+}$and $\mathrm{Cl}^{-}$accumulations in shoots at the maturity stage and grain yield [16]. Under salt stress conditions, $\mathrm{Na}^{+}$and $\mathrm{Cl}^{-}$contents at the full heading stage were found to correlate more strongly with grain yield than those at the panicle initiation and mature stages [26]. In agreement with the above findings, our result suggests that the maintained grain yield and yield components in the salt-tolerant CSSLs could be attributed to low $\mathrm{Na}^{+}$and $\mathrm{Cl}^{-}$accumulations in the leaf and whole plant at the full heading stage. By minimizing the entry of $\mathrm{Na}^{+}$through roots, $\mathrm{Na}^{+}$is sequestered in roots, and reabsorption occurs from the plant xylem stream that could maintain a low $\mathrm{Na}^{+}$ concentration in shoots $[8,44]$. Large yield biomass was proposed to form an advantage in diluting the accumulated $\mathrm{Na}^{+}$and providing storage capacity for its sequestration [23,48]. As the IR64 chromosome segments on these tolerant CSSLs are still large, QTL analysis using an $\mathrm{F}_{2}$ population and the development of NILs provide a productive approach for validating and narrowing down the QTL regions.

Finding QTLs controlling yield and yield components under salt stress conditions with stable effects would be valuable for developing salt-tolerant varieties through marker assistance. Salt stress reduces grain yield and yield components such as panicle number, grain number per panicle, the percentage of ripened grains, and 1000-grain weight, and the contribution of each component to grain yield varies among different varieties and growing environments $[9,10,14,59]$. Using NILs, we detected $q S T G F 2$, closely associated 
with the significant increase in GF of NIL3 and NIL4 (Figure 5). Besides this, several studies have suggested that QTLs controlling grain yield and yield components are often mapped as a cluster in the genome, which points toward the effects of either tightly linked genes or one gene controlling these traits [42,44,60]. Here, qSTGF2 and qSTGY2.2 were mapped closely. We also found a highly positive correlation between GY and GF $\left(R^{2}=0.859\right.$, Table 4$)$, which suggests that GF is an important contributor to maintaining GY in this variety. Further research on genes relating to grain filling maintenance under salinity, which is not yet understood, is needed to reveal the major controlling genes and their regulatory mechanisms.

Table 4. Pearson correlation coefficients between grain yield and ancillary traits of Koshihikari and NILs under salt stress conditions in 2018. Values are mean \pm standard error $(\mathrm{n}=4) . * * *$, and *** indicate significant differences at the $5 \%, 1 \%$, and $0.1 \%$ levels, respectively.

\begin{tabular}{cccccccc}
\hline & DW & PN & PW & GY & GF & TGW & SN \\
\hline DW & 1 & & & & & & \\
PN & $0.675^{*}$ & 1 & & & & & \\
PW & 0.433 & 0.368 & 1 & & & & \\
GY & 0.275 & 0.173 & $0.950^{* * *}$ & 1 & & & \\
GF & -0.061 & -0.289 & $0.698^{* * *}$ & $0.859^{* * *}$ & 1 & & \\
TGW & 0.072 & 0.163 & -0.312 & -0.323 & -0.438 & 1 & \\
SN & 0.250 & -0.204 & $0.582^{* *}$ & $0.548^{*}$ & $0.542^{*}$ & -0.431 & 1 \\
\hline
\end{tabular}

The QTL for another major yield component, $q S T P N 2$, was fine-mapped to a $0.6 \mathrm{Mb}$ region flanked by RM13717 and Indel 27.25 (Figure 5). It is well known that shoot branching determining the panicle number is under the control of complex interactions between phytohormones and is affected by environmental factors, developmental status, and genetic factors [61]. To withstand salt stress, plants must address the major problems of ionic, osmotic, and oxidative stresses. According to the rice genome annotation database, there are 103 genes in the qSTPN2 region. Among them, we found some candidate genes engaging in alleviating osmotic and oxidative damage, which could help maintain better growth and result in shoot branching. For example, a gene involved in osmoprotection, OSTPP1, was reported to be induced by salt stress, and its overexpression resulted in enhanced salt tolerance [62]. A gene encoding for aquaporin regulating water balance, OsPIP1;1, whose moderate expression increased salt tolerance, also exists in the QTL region [63]. Kumars et al. [64] suggested that $O s D h n 1$ is an important gene for salt tolerance in rice as it might relate to ROS scavenging and alleviate oxidative damage. The OsTPP1 and OsDhn1 were reported to be upregulated in shoot and root in response to salt stress [65]. All these suggested that OsTPP1 and OsDhn1 might be the most likely candidate genes of $q S T P N 2$. Examining the key genetic effects and cloning of $q S T P N 2$ will facilitate molecular breeding for higher panicle numbers under salt stress in rice.

\section{Conclusions}

Taken together, the results indicate that IR64 possesses potential genetic factors conferring salt tolerance at the vegetative and reproductive stages. Two promising IR64 CSSLs, SL2007 and SL2038, maintained better DW, GY, and yield components than Koshihikari under salinity conditions, which could be mainly attributed to low $\mathrm{Na}^{+}$and $\mathrm{Cl}^{-}$contents in the leaf and whole plant at the full heading stage. From the SL2007/Koshihikari $F_{2}$ population, QTL analysis detected six QTLs for GY and ancillary traits crowding around two genome regions of chromosome 2. The major QTL for GY, qSTGY2.2, was delimited to a $2.5 \mathrm{Mb}$ region, and two novel QTLs for yield components, qSTPN2 and qSTGF2, were delimited to a $0.6 \mathrm{Mb}$ region and a $2.3 \mathrm{Mb}$ region, respectively. Besides this, in SL2007, among its yield components, maintained GF might be primarily responsible for the better GY under salt stress conditions. Our results not only help us to interpret the genetics 
and mechanisms underlying salt tolerance in rice but also provide valuable materials for breeding programs.

Author Contributions: Conceptualization, Y.H.; Methodology, Y.H., N.T.T.T. and N.S.M.; Software, N.S.M.; Formal Analysis, M.N., K.K. and N.S.M.; Investigation, D.D.H., M.N., K.K. and N.S.M.; Data Curation, Y.H. and N.S.M.; Writing-Original Draft Preparation, N.S.M.; Writing-Review and Editing, Y.H., T.K., K.S. and N.S.M.; Supervision, Y.H.; Funding Acquisition, Y.H. All authors have read and agreed to the published version of the manuscript.

Funding: This work was funded by JSPS KAKENHI Grant Number JP16K07573, JP20H02969.

Institutional Review Board Statement: Not applicable.

Conflicts of Interest: The authors declare no conflict of interest.

\section{References}

1. GRiSP. Rice Almanac, 4th ed.; International Rice Research Institute: Los Baños, Philippines, 2013.

2. United Nations, Department of Economic and Social Affairs, Population Division. World Population Prospects: The 2012 Revision Highlights and Advance Tables; Working Paper No. ESA/P/WP.228; Department of Economic \& Social Affairs: New York, NY, USA, 2013.

3. Ray, D.K.; Mueller, N.D.; West, P.C.; Foley, J.A. Yield trends are insufficient to double global crop production by 2050. PLoS ONE 2013, 8, 6. [CrossRef] [PubMed]

4. Pessarakli, M. Handbook of Plant and Crop Stress, 2nd ed.; Marcel Dekker Inc.: New York, NY, USA, 1999.

5. Rehman, S.; Harris, P.J.C.; Ashraf, A. Stress environments and their impact on crop production. In Abiotic Stress: Plant Resistance Through Breeding and Molecular Approaches; Food Products Press: New York, NY, USA, 2005.

6. Muthayya, S.; Sugimoto, J.D.; Montgomery, S.; Maberly, G.F. An overview of global rice production, supply, trade, and consumption. Ann. N. Y. Acad. Sci. 2014, 1324, 7-14. [CrossRef] [PubMed]

7. Kumar, V.; Singh, A.; Mithra, S.V.A.; Krishnamurthy, S.L.; Parida, S.K.; Jain, S.; Tiwari, K.K.; Kumar, P.; Rao, A.R.; Sharma, S.K.; et al. Genome-wide association mapping of salinity tolerance in rice (Oryza sativa). DNA Res. 2015, 22, 133-145. [CrossRef] [PubMed]

8. Reddy, I.N.B.L.; Kim, B.K.; Yoon, I.S.; Kim, K.H.; Kwon, T.R. Salt tolerance in rice: Focus on mechanisms and approaches. Rice Sci. 2017, 24, 123-144. [CrossRef]

9. Heenan, D.P.; Lewin, L.G.; McCaffery, D.W. Salinity tolerance in rice varieties at different growth stages. Aust. J. Exp. Agric. 1988, 28, 343-349. [CrossRef]

10. Makihara, D.; Tsuda, M.; Morita, M.; Hirai, Y.; Kuroda, T. Effect of salinity on the growth and development on rice (Oryza sativa L.) varieties. Jpn. J. Trop. Agric. 1999, 43, 285-294.

11. Singh, R.K.; Flowers, T.J. Physiology and Molecular Biology of the Effects of Salinity on Rice, 3rd ed.; Taylor \& Francis: Boca Raton, FL, USA, 2010.

12. Zeng, L.; Shannon, M.C.; Grieve, C.M. Evaluation of salt tolerance in rice genotypes by multiple agronomic characters. Euphytica 2002, 127, 235-245. [CrossRef]

13. Mohammadi, R.; Mendioro, M.S.; Diaz, G.Q.; Gregorio, Q.B.; Singh, R.K. Genetic analysis of salt tolerance at seedling and reproductive stages in rice (Oryza sativa). Plant Breed. 2014, 133, 548-559. [CrossRef]

14. Khatun, S.; Rizzo, C.A.; Flowers, T.J. Genotypic variation in the effect of salinity on fertility in rice. Plant Soil. 1995, 173, 239-250. [CrossRef]

15. Lutts, S.; Kinet, J.M.; Bouharmont, J. Changes in plant response to NaCI during development of rice (Oryza sativa L.) varieties differing in salinity resistance. J. Exp. Bot. 1995, 46, 1843-1852. [CrossRef]

16. Kumar, V.; Khare, T. Differential growth and yield responses of salt-tolerant and susceptible rice cultivars to individual (Na+ and $\mathrm{Cl}-$ ) and additive stress effects of NaCl. Acta Physiol. Plant. 2016, 38, 7. [CrossRef]

17. Hussain, S.; Jun-hua, Z.; Chu, Z.; Lian-Feng, Z.; Xiao-Chuang, C.; Sheng-Miao, Y.; James, A.B.; Ji-Jie, H.; Qian-Yu, J. Effects of salt stress on rice growth, development characteristics, and the regulating ways: A review. J. Integr. Agric. 2017, 16, 2357-2374. [CrossRef]

18. Amirjani, M.R. Effect of Salinity stress on growth, sugar content, pigments and enzyme activity of rice. Int. J. Bot. 2011, 7, 73-81. [CrossRef]

19. Gupta, B.; Huang, B. Mechanism of salinity tolerance in plants: Physiological, biochemical, and molecular characterization. Int. J. Genomics. 2014, 2014, 1-18. [CrossRef] [PubMed]

20. Munns, R.; Tester, M. Mechanisms of Salinity Tolerance. Annu. Rev. Plant Biol. 2008, 59, 651-681. [CrossRef] [PubMed]

21. Flowers, T.J.; Yeo, A.R. Variability in the resistance of sodium chloride salinity within rice (Oryza sativa L.) varieties. Neww Phytol. 1981, 88, 363-373. [CrossRef]

22. Ueda, A.; Yahagi, H.; Fujikawa, Y.; Nagaoka, T.; Esaka, M.; Calcaño, M.; González, M.M.; Martich, J.D.H.; Saneoka, H. Comparative physiological analysis of salinity tolerance in rice. Soil Sci. Plant Nutr. 2013, 59, 896-903. [CrossRef] 
23. Platten, J.D.; Egdane, J.A.; Ismail, A.M. Salinity tolerance, Na+ exclusion and allele mining of HKT1;5 in Oryza sativa and O. glaberrima: Many sources, many genes, one mechanism? BMC Plant Biol. 2013, 13, 32. [CrossRef]

24. Mekawy, A.M.M.; Assaha, D.V.M.; Yahagi, H.; Tada, Y.; Ueda, A.; Saneoka, H. Growth, physiological adaptation, and gene expression analysis of two Egyptian rice cultivars under salt stress. Plant Physiol. Biochem. 2015, 87, 17-25. [CrossRef] [PubMed]

25. Gerona, M.E.B.; Deocampo, M.P.; Egdane, J.A.; Ismail, A.M.; Dionisio-Sese, M.L. Physiological Responses of Contrasting Rice Genotypes to Salt Stress at Reproductive Stage. Rice Sci. 2019, 26, 207-219. [CrossRef]

26. Thuy, N.T.T.; Tokuyasu, M.; Mai, N.S.; Hirai, Y. Identification and characterization of chromosome regions associated with salinity tolerance in rice. J. Agric. Sci. 2018, 10, 57-68. [CrossRef]

27. Lin, H.X.; Zhu, M.Z.; Yano, M.; Gao, J.P.; Liang, Z.W.; Su, W.A.; Hu, X.H.; Ren, Z.H.; Chao, D.Y. QTLs for Na+ and K+ uptake of the shoots and roots controlling rice salt tolerance. Theor. Appl. Genet. 2004, 108, 253-260. [CrossRef]

28. Lee, S.Y.; Ahn, J.H.; Cha, Y.S.; Yun, D.W.; Lee, M.C.; Ko, J.C.; Lee, K.S.; Eun, M.Y. Mapping of quantitative trait loci for salt tolerance at the seedling stage in rice. Mol. Cells. 2006, 21, 192-196. [PubMed]

29. Kim, D.M.; Ju, H.G.; Kwon, T.R.; Oh, C.S.; Ahn, S.N. Mapping QTLs for salt tolerance in an introgression line population between Japonica cultivars in rice. J. Crop Sci. Biotechnol. 2009, 12, 121-128. [CrossRef]

30. Cheng, L.; Wang, Y.; Meng, L.; Hu, X.; Cui, Y.; Sun, Y.; Zhu, L.; Ali, J.; Xu, J.; Li, Z. Identification of salt-tolerant QTLs with strong genetic background effect using two sets of reciprocal introgression lines in rice. Genome 2012, 55, 45-55. [CrossRef]

31. Leon, T.B.D.; Linscombe, S.; Subudhi, P.K. Identification and validation of QTLs for seedling salinity tolerance in introgression lines of a salt tolerant rice landrace 'Pokkali'. PLoS ONE 2017, 12, 1-30.

32. Puram, V.R.R.; Ontoy, J.; Subudhi, P.K. Identification of QTLs for salt tolerance traits and prebreeding lines with enhanced salt tolerance in an introgression line population of rice. Plant Mol. Biol. Report. 2018, 36, 695-709. [CrossRef]

33. Rahman, M.A.; Thomson, M.J.; Ocampo, M.D.; Egdane, J.A.; Salam, M.A.; Shah-E-Alam, M.; Ismail, A.M. Assessing trait contribution and mapping novel QTL for salinity tolerance using the Bangladeshi rice landrace Capsule. Rice 2019, 12, 12-63. [CrossRef] [PubMed]

34. $\mathrm{Wu}, \mathrm{F}$; Yang, J.; Yu, D.; Xu, P. Identification and validation a major QTL from 'Sea Rice 86' seedlings conferred salt tolerance. Agronomy 2020, 10, 410. [CrossRef]

35. Yuan, J.; Wang, X.; Zhao, Y.; Khan, N.U.; Zhao, Z.; Zhang, Y.; Wen, X.; Tang, F.; Wang, F.; Li, Z. Genetic basis and identification of candidate genes for salt tolerance in rice by GWAS. Sci. Rep. 2020, 10, 1-9. [CrossRef] [PubMed]

36. Nakhla, W.R.; Sun, W.; Fan, K.; Yang, K.; Zhang, C.; Yu, S. Identification of QTLs for salt tolerance at the germination and seedling stages in rice. Plants 2021, 10, 428. [CrossRef]

37. Bonilla, P.; Dvorak, J.; Mackill, D.; Deal, K.; Gregorio, G. RFLP and SSLP mapping of salinity tolerance genes in chromosome 1 of rice (Oryza sativa L.) using recombinant inbred lines. Philipp. Agric. Sci. 2002, 65, 68-76.

38. Sevanthi, A.M.; Prakash, C.; Shanmugavadivel, C. Recent progress in rice varietal development for abiotic stress tolerance. In Advances in Rice Research for Abiotic Stress Tolerance; Woodhead Publishing: Duxford, UK, 2019; pp. 47-68.

39. Krishnamurthy, S.L.; Pundir, P.; Warraich, A.S.; Rathor, S.; Lokeshkumar, B.M.; Singh, N.K.; Sharma, P.C. Introgressed Saltol QTL lines improves the salinity tolerance in rice at seedling stage. Front. Plant Sci. 2020, 11, 1-13. [CrossRef]

40. Ren, Z.H.; Gao, J.P.; Li, L.G.; Cai, X.L.; Huang, W.; Chao, D.Y.; Zhu, M.Z.; Wang, Z.Y.; Luan, S.; Lin, H.X. A rice quantitative trait locus for salt tolerance encodes a sodium transporter. Nat. Genet. 2005, 37, 1141-1146. [CrossRef] [PubMed]

41. Jing, W.; Deng, P.; Cao, C.; Zhang, W. Fine mapping of $q S K C-1$, a major quantitative trait locus for shoot K+ concentration, in rice seedlings grown under salt stress. Breed. Sci. 2017, 67, 286-295. [CrossRef]

42. Mohammadi, R.; Mendioro, M.S.; Diaz, G.Q.; Gregorio, G.B.; Singh, R.K. Mapping quantitative trait loci associated with yield and yield components under reproductive stage salinity stress in rice (Oryza sativa L.). J. Genet. 2013, 92, 433-443. [CrossRef]

43. Bimpong, I.K.; Manneh, B.; Diop, B.; Ghislain, K.; Sow, A.; Amoah, N.K.A.; Gregorio, G.; Singh, R.K.; Ortiz, R.; Wopereis, M. New quantitative trait loci for enhancing adaptation to salinity in rice from Hasawi, a Saudi landrace into three African cultivars at the reproductive stage. Euphytica 2014, 200, 45-60. [CrossRef]

44. Hossain, H.; Rahman, M.A.; Alam, M.S.; Singh, R.K. Mapping of quantitative trait loci associated with reproductive-stage salt tolerance in rice. J. Agron. Crop Sci. 2015, 201, 17-31. [CrossRef]

45. Chattopadhyay, K.; Mohanty, S.K.; Vijayan, J.; Marndi, B.C.; Sarkar, A.; Molla, K.A.; Chakraborty, K.; Ray, S.; Sarkar, R.K. Genetic dissection of component traits for salinity tolerance at reproductive stage in rice. Plant Mol. Biol. Report. 2021, 39, 386-402. [CrossRef]

46. Mondal, S.; Borromeo, T.H.; Diaz, M.G.Q.; Amas, J.; Rahman, M.A.; Thomson, M.J.; Gregorio, G.B. Dissecting qtls for reproductive stage salinity tolerance in rice from BRRI dhan 47. Plant Breed. Biotechnol. 2019, 7, 302-312. [CrossRef]

47. Noor, A.U.Z.; Jewel, G.M.N.A.; Haque, T.; Elias, S.M.; Biswas, S.; Rahman, M.S.; Seraj, Z.I. Validation of QTLs in Bangladeshi rice landrace Horkuch responsible for salt tolerance in seedling stage and maturation. Acta Physiol. Plant. 2019, 41, 1-15. [CrossRef]

48. Yeo, A.R.; Yeo, M.E.; Flowers, S.A.; Flowers, T.J. Screening of rice (Oryza sativa L.) genotypes for physiological characters contributing to salinity resistance, and their relationship to overall performance. Theor. Appl. Genet. 1990, 79, 377-384. [CrossRef] [PubMed]

49. Prusty, M.R.; Kim, S.R.; Vinarao, R.; Entila, F.; Egdane, J.; Diaz, M.G.Q.; Jena, K.K. Newly identified wild rice accessions conferring high salt tolerance might use a tissue tolerance mechanism in leaf. Front. Plant Sci. 2018, 9, 1-15. [CrossRef]

50. Mackill, D.J.; Khush, G.S. IR64: A high-quality and high-yielding mega variety. Rice 2018, 2018, 11-18. [CrossRef] [PubMed] 
51. Nagata, K.; Ando, T.; Nonoue, Y.; Mizubayashi, T.; Kitazawa, N.; Shomura, A.; Matsubara, K.; Ono, N.; Mizobuchi, R.; Shibaya, T.; et al. Advanced backcross QTL analysis reveals complicated genetic control of rice grain shape in a japonica $\times$ indica cross. Breed. Sci. 2015, 65, 308-318. [CrossRef] [PubMed]

52. Shavrukov, Y.; Gupta, N.K.; Miyazaki, J.; Baho, M.N.; Chalmers, K.J.; Tester, M.; Langridge, P.; Collins, N.C. HvNax3-A locus controlling shoot sodium exclusion derived from wild barley (Hordeum vulgare ssp. spontaneum). Funct. Integr. Genomics 2010, 10, 277-291. [CrossRef] [PubMed]

53. Chai, L.; Zhang, J.; Pan, X.; Zhang, F.; Zheng, T.; Zhao, X.; Wang, W.; Jauhar, A.; Xu, J.; Li, Z. Advanced backcross QTL analysis for the whole plant growth duration salt tolerance in rice (Oryza sativa L.). J. Integr. Agric. 2014, 13, 1609-1620. [CrossRef]

54. Pundir, P.; Devi, A.; Krishnamurthy, S.L.; Sharma, P.C.; Vinaykumar, N.M. QTLs in salt rice variety CSR10 reveals salinity tolerance at reproductive stage. Acta Physiol. Plant. 2021, 43, 1-15. [CrossRef]

55. Mai, N.S.; Hirai, Y. QTL mapping for salt tolerance at reproductive stage in rice: A Minireview. J. Environ. Sci. Sustain. Soc. 2021, $10,31-34$.

56. Takai, T.; Nonoue, Y.; Yamamoto, S.; Yamanouchi, U.; Matsubara, K.; Liang, Z.W.; Lin, H.; Ono, N.; Uga, Y.; Yano, M. Development of Chromosome segment substitution lines derived from backcross between indica donor rice cultivar 'Nona Bokar' and japonica recipient cultivar 'Koshihikari'. Jpn. Soc. Breed. 2007, 57, 257-261. [CrossRef]

57. Ismail, A.M.; Horie, T. Genomics, physiology, and molecular breeding approaches for improving salt tolerance. Annu. Rev. Plant Biol. 2017, 68, 405-434. [CrossRef] [PubMed]

58. Horie, T.; Karahara, I.; Katsuhara, M. Salinity tolerance mechanisms in glycophytes: An overview with the central focus on rice plants. Rice 2012, 5, 1-18. [CrossRef]

59. Zeng, L.; Shannon, M.C. Salinity effects on seedling growth and yield components of rice. Crop Sci. 2000, 40, 996-1003. [CrossRef]

60. Fahad, S.; Adnan, M.; Noor, M.; Arif, M.; Alam, M.; Khan, I.A.; Ullah, H.; Wahid, F.; Mian, I.A.; Jamal, Y.; et al. Major constrains for global rice production. In Advances in Rice Research for Abiotic Stress Tolerance; Woodhead Publishing: Duxford, UK, 2019.

61. Xing, Y.; Zhang, Q. Genetic and molecular bases of rice yield. Annu. Rev. Plant Biol. 2010, 61, 421-442. [CrossRef] [PubMed]

62. Ge, L.F.; Chao, D.Y.; Shi, M.; Zhu, M.Z.; Gao, J.P.; Lin, H.X. Overexpression of the trehalose-6-phosphate phosphatase gene OsTPP1 confers stress tolerance in rice and results in the activation of stress responsive genes. Planta 2008, 228, 191-201. [CrossRef] [PubMed]

63. Liu, C.; Fukumoto, T.; Matsumoto, T.; Gena, P.; Frascaria, D.; Kaneko, T.; Katsuhara, M.; Zhong, S.; Sun, X.; Zhu, Y.; et al. Aquaporin OsPIP1;1 promotes rice salt resistance and seed germination. Plant Physiol. Biochem. 2013, 63, 151-158. [CrossRef] [PubMed]

64. Kumar, M.; Lee, S.C.; Kim, J.Y.; Kim, S.J.; Aye, S.S.; Kim, S.R. Over-expression of dehydrin gene, OsDhn1, improves drought and salt stress tolerance through scavenging of reactive oxygen species in rice (Oryza sativa L.). J. Plant Biol. 2014, 57, 383-393. [CrossRef]

65. Mizuno, H.; Kawahara, Y.; Sakai, H.; Kanamori, H.; Wakimoto, H.; Yamagata, H.; Oono, Y.; Wu, J.; Ikawa, H.; Itoh, T.; et al. Massive parallel sequencing of mRNA in identification of unannotated salinity stress-inducible transcripts in rice (Oryza sativa L.). BMC Genomics 2010, 11, 683. [CrossRef] [PubMed] 